\title{
Textos fundamentales del psicoanálisis I: Más allá del principio de placer (1920) de Sigmund Freud
}

\author{
Psychoanalytic Fundamental Texts: Beyond the Pleasure Principle (1920) by Sigmund Freud \\ Jesús Cisneros-Herrera ${ }^{a}$ Gelacio Guzmán-Díaz $^{b}$
}

\begin{abstract}
:
This paper presents a review of Beyond the Pleasure Principle, a metapsychological text published in 1920 by Sigmund Freud. The importance of that work lies in the introduction of the life drives - death drives duality in psychoanalytical theory, which substituted for the sexual drives - ego drives dichotomy. The last section presents a reflection that comes out more from doubts and questions than from conclusions about the subject. Despite the great advances in psychoanalytic theory, there are still fundamental aspect that need to be cleared. This is the first of a series of essays that will be aimed at presenting fundamental texts of psychoanalysis, not only by Freud, but also by other psychoanalysts that have made essential contributions to psychoanalytic theory.
\end{abstract}

Keywords:

Psychoanalysis, life drive, death drive, pleasure principle, Sigmund Freud

\section{Resumen:}

En este artículo se hace una reseña de Más allá del principio de placer, texto metapsicológico publicado en 1920 por Sigmund Freud. La importancia de ese trabajo radica en la introducción de la dualidad pulsión de vida - pulsión de muerte en la teoría psicoanalítica, que sustituyó a la dicotomía pulsiones sexuales - pulsiones del yo. Al final, se presenta una reflexión que da cuenta más de inquietudes actuales que de conclusiones. A pesar de los grandes desarrollos teóricos del psicoanálisis, existen aspectos fundamentales que es necesario aclarar. Éste es el primero de una serie de ensayos que se dedicarán a comentar textos fundamentales del psicoanálisis, no sólo de Freud, sino de otros autores que han hecho contribuciones esenciales a la teoría psicoanalítica.

\section{Palabras Clave:}

Psicoanálisis, pulsión de vida, pulsión de muerte, principio de placer, Sigmund Freud

\section{Breve crítica de la psicología}

La psicología actual se caracteriza por la ingente cantidad de enfoques, "teorías", perspectivas y técnicas de intervención que rivalizan, se contradicen, se combinan, se complementan, se fusionan o, incluso, se ignoran entre sí. En gran parte de las investigaciones, el resultado estadístico dicta lo aceptable y lo no aceptable a tal grado que la búsqueda de unidad y coherencia a la que toda ciencia debe aspirar, cuando no ha sido olvidada, ha quedado relegada en segundo o tercer plano.

Una vía para buscar esa unidad es conocer y repensar textos importantes en su época que han dejado de leerse debido a una supuesta obsolescencia frente a las modernas "teorías" e investigaciones. A causa de este desconocimiento, los psicólogos en formación caen presas de una fascinación por lo nuevo que les impide desarrollar un juicio crítico. Una práctica común en la psicología, cuyo máximo exponente es la terapia cognitivo-conductual, es emplear términos técnicos nuevos para nombrar conceptos antes desarrollados para darles un aire de actualidad y cientificismo que ayuda a su aceptación en la comunidad científica y en la sociedad general.

En esta tendencia de la psicología, el psicoanálisis se encuentra con intentos sistemáticos de desacreditarlo

a Universidad Autónoma del Estado de Hidalgo, Escuela Superior de Atotonilco de Tula, https://orcid.org/0000-0003-1370-8086, Email: jesus_cisneros@uaeh.edu.mx

b Universidad Autónoma del Estado de Hidalgo, Escuela Superior de Atotonilco de Tula, https://orcid.org/0000-0003-4869-8658, Email: gelacio_guzman@uaeh.edu.mx 
como una práctica carente de evidencias científicas, entendiendo como tales los productos de la "medición" y análisis estadísticos de resultados de muestras más o menos grandes. El problema radica en que, hasta ahora, los psicólogos no han sido capaces de reconocer y aceptar la especificidad de los fenómenos que constituyen su objeto de estudio. Dicha especificidad exige métodos adecuado para su estudio, métodos que se adapten al objeto y no que obliguen al objeto a adaptarse a ellos.

\section{Inserción de Freud en la psicología}

Sigmund Freud, (1856-1939), alejado de las preocupaciones superficiales de la época en cuanto a aplicar el método experimental y hacer mediciones de fenómenos psicológicos para que la psicología alcanzara el estatus de ciencia -sin embargo, con el mismo espíritu científico de Galileo o Darwin-, creó un tratamiento para los trastornos psicológicos de su época que, a la postre, resultó ser al mismo tiempo un método de investigación que respetó, por fin, su objeto de estudio. Freud reconoció la tremenda importancia de la palabra en la vida del ser humano. Una palabra puede dar dicha o tristeza, infunde miedo o da tranquilidad, transmite amor u odio, trae orden o confusión a la vida. Para el trabajo terapéutico, las (im)posibilidades de decir se traducen en síntomas, sufrimiento $o$ alivio.

Freud dedicó prácticamente toda su carrera, después de un breve paso por la fisiología-que tuvo que abandonar debido a que su condición de ju dío no le au guraba un buen porvenir-, a la investigación de los padecimientos psicológicos, histeria, fobias y neurosis obsesivas principalmente. En 1895 publicó en coautoría con Joseph Bruer, otro médico vienés, Estudios sobre la histeria, y escribió en su correspondencia con Wilhelm Fliess lo que se denominó póstumamente Proyecto de psicología para neurólogos, que ahora simplemente se titula Proyecto de psicología.

En 1899 se publicó, aunque la fecha oficial es 1900, La interpretación de los sueños, que se considera el texto fundante del psicoanálisis. Otros escritos de gran importancia en la evolución del pensamiento freudiano son Tres ensayos de teoría sexual (1905), Introducción del narcisismo (1914) y la serie de textos metapsicológicos Pulsiones y destinos de pulsión (1914), La represión (1914), Lo inconciente (1914), Duelo y melancolía (1915) y Complemento metapsicológico a la doctrina de los sueños (1917).

Hasta este punto, el pensamiento de Freud estaba dominado por la división del aparato psíquico en consciente, preconsciente e inconsciente -primera tópica-y la dicotomía planteada entre pulsiones sexuales y pulsiones del yo, justificadas en parte por su relación con la adaptación darwiniana. Por una parte, las pulsiones sexuales están al servicio de la supervivencia de la especie; por otra, las pulsiones del yo se encaminan a la supervivencia del individuo.

Sin embargo, el concepto de narcisismo y el estudio de la melancolía pronto resultaron en una segunda tópica-ello, yo y superyó-que reordenó la teoría psicoanalítica. Pero antes de El yo y el ello (1923), donde propuso la segunda tópica, Freud hizo otro planteamiento que provocó un cisma entre sus discípulos y seguidores. Se trató de la polémica pulsión de muerte, en la cual quedaron subsumidas las pulsiones del yo y verdadero contrario de la pulsión sexual.

\section{Más allá del principio de placer}

Más allá del principio de placer (Jenseits des Lustprinzips) apareció en 1920.

El texto comienza con la explicación del principio de placer, tal como lo hizo en Formulaciones sobre los dos principios del acaecer psíquico (1). Este principio, regula los procesos psíquicos: más allá de cierto umbral, la tensión acumulada se torna displacentera, por lo que se descargar total 0 parcialmente. El placer queda identificado como la reducción de la tensión a niveles tolerables. En otras palabras, "el aparato an ímico se afana por mantener lo más baja posible, o al menos constante, la cantidad de excitación en él" (2). Estas ideas aparecieron en 1895, en el Proyecto de psicología, bajo las denominaciones de principio de inercia -la tendencia a regresar al estado de reposo libre de toda estimulación, irrealizable en última instancia-y principio de constancia -relevo del principio de inercia que se conforma con mantener la tensión en niveles bajos.

El principio de placer es sustituido por el principio de realidad, el cual no implica la renuncia al placer, sino implica procesos de pensamiento que permiten demorar la descarga, atender a las normas sociales, conformarse con satisfacciones parciales $y$, a veces, renunciar a la satisfacción (1). El principio de realidad ya implica la existencia de una unidad coherente que hace que ciertas formas de descarga de la tensión sean inconciliables con ella. De modo que ciertas satisfacciones que de suyo deberían ser sentidas como placer, producen en realidad displacer en el yo, que ya nada tiene que ver con las fuentes somáticas de la tensión, como Freud postuló en Pulsiones y destinos de pulsión (3). Por lo tanto, es un displacer puramente psíquico, una tensión que proviene de la reducción de otra tensión que resulta inaceptable y, por lo tanto, inconciliable con el yo. Para evitar este conflicto, opera la represión; sin embargo, en realidad no se evita, sino que se invierte, pero ahora los dos términos quedan en distintos planos: la tensión cuya descarga se rechaza permanece en lo inconsciente, pero produce displacer, mientras que en lo consciente se mantiene el 
equilibrio aunque sin sentir placer por haber rechazado la exigencia inaceptable puesto que ignora su presencia en lo inconsciente como reprimido.

En la siguiente sección, Freud aborda las experiencias trau máticas, cuyas secuelas no se ajustan al principio de placer. Los sueños que recrean esas experiencias también producen la angustia y el terror que las acompañaron, justo lo contrario de la satisfacción de deseos postulada por el propio Freud (4) como aquello que se expresa en todo sueño. Un fenómeno afín a estos sueños es el juego que Freud observó en su nieto: primero arrojaba sus juguetes fuera de su cuna emitiendo "un fuerte y prolongado 'o-o-o-o'” (p. 14) que correspon día al adverbio alemán fort, cuyo significado en español es haberse ido o marchado, estar ausente, haberse perdido. Después, con un hilo atado a un carretel hacía este mismo juego, pero lo complementaba con "un amistoso Da", adverbio antónimo de fort. La conclusión de Freud fue que el juego del carretel representaba la partida de la madre, experiencia dolorosa para todo niño, y su regreso. Por tanto, este juego tampoco se guiaba, en la perspectiva de Freud, por el principio de placer. Está presente, en cambio, la abreacción del dolor cau sado por la experiencia al mismo tiempo que el niño se adueña de la situación cambiando el papel pasivo por uno activo.

En el capítulo III, Freud expone lo que llamó compulsión de repetición que se manifestaba en la transferencia, expuesto antes en Recordar, repetir, reelaborar (5). "El enfermo no puede recordar todo lo que hay en él de reprimido... Más bien se ve forzado a repetir lo reprimido como vivencia presente, en vez de recordarlo" (2). Esta reedición del pasado no sólo es de escenas que implican un alivio de tensión que, aunque produce displacer en el yo, también produce placer, sino de experiencias que sólo pueden causar displacer, como "causarse de nuevo la impresión del desaire" (2).

A partir del capítu lo IV, empieza la especulación freudiana. "La especulación psicoanalítica arranca de la impresión, recibida a raíz de procesos inconscientes, de que la conciencia no puede ser el carácter más universal de los procesos anímicos, sino sólo una función particular de ellos" (2). La conciencia está íntimamente ligada a los sistemas perceptuales y su naturaleza radica en que las sensaciones y percepciones la ocupan fugazmente, pues siempre está disponible para nuevos estímulos, tema que Freud abordó posteriormente en Nota sobre la "pizarra mágica"(1925). La explicación de esta particularidad de la conciencia ya había sido adelantada en el Proyecto de psicología (6), pero referida a la percepción. Las huellas mnémicas son resultado, planteó Freud, de la modificación de las barreras que cierran el paso a la energía entre una neurona y otra, barreras-contacto las llamó Freud en ese manuscrito. Una vez que un estímulo ha sido lo suficientemente intenso para pasar de una neurona a otra, queda abierto el camino para las repeticiones de ese estímulo. Sin embargo, las neuronas conectadas con los sistemas perceptuales y que son el asiento orgánico de la conciencia no poseen tales barreras, por lo que los estímulos tienen camino libre para atravesarlas y no hay posibilidad de modificarlas.

Ahora bien, los organismos han desarrollado una protección antiestímulos para atenuar la energía que ingresa al organismo de modo que sea manejable en su interior. Cualquier excitación externa con la fuerza suficiente para perforar la protección antiestímulo es traumática, puesto que desborda la organización intema. "Ya no podrá impedirse que el aparato anímico resulte anegado por grandes volúmenes de estímulo; entonces, la tarea planteada es más bien esta otra: dominar el estímulo, ligar psíquicamente los volúmenes de estímulo que penetraron violentamente a fin de conducirlos, después, a su tramitación" (2). Sin embargo, tal dominio del estímulo no siempre se consigue y el yo queda ineme, en mayor o menor medida, ante las huellas de la experiencia traumática.

En el capítulo V, Freud plantea la oposición entre compulsión de repetición y principio de placer:

Resulta claro que [en el analizado] su compulsión a repetir en la transferencia los episodios del periodo infantil de su vida se sitúa, en todos los sentidos, más allá del principio de placer. El enfermo se comporta en esto de una manera completamente infantil, y así se nos enseña que las huellas mnémicas reprimidas de sus vivencias del tiempo primordial no subsisten en su interior en el estado ligado, y aun, en cierta medida, son insusceptibles del proceso secundario. A esta condición de no ligadas deben también su capacidad de formar, adhiriéndose a los restos diurnos, una fantasía de deseo que halla figuración en el sueño. (2)

La conclusión a la que llega Freud a partir de este razonamiento plantea un agregado profundo, cuando no un cambio radical, en su concepción de las pulsiones: "Una pulsión sería entonces un esfuerzo, inherente a lo orgánico vivo, de reproducción de un estado anterior que lo vivo debió resignar bajo el influjo de fuerzas perturbadoras externas" (2). Años antes, Freud (3) había postulado como componentes de la pulsión la fuente orgánica, la meta, el objeto y el intraducible Drang, que José Luis Etcheverry tradujo cuestionablemente como esfuerzo. La meta es siempre la satisfacción por medio de un objeto en el que se descarga la tensión o el Drang, pero la pulsión en sí misma no tiene un objetivo o un propósito, sino que su existencia constituye una exigencia para el aparato psíquico que solo termina cuando desaparece o se reduce lo suficiente la energía pulsional acumulada.

La pulsión no es un ente cognoscente que busque regresar a un estado previo; en todo caso, es el yo quien 
podría hacerlo. Y plantear la pulsión como una especie de intencionalidad biológica de los seres vivos para volver al estado inanimado libre para siempre de tensiones es llevar demasiado lejos la especulación. Además, incluso atreviéndonos a especular al respecto, lo que se observa es que la vida se mantiene incluso en condiciones muy adversas. Sólo para el ser humano, la muerte puede ser una elección; en el resto de los organismos la muerte es la imposibilidad de seguir viviendo.

En la argumentación freudiana, las pulsiones que aparentemente preservaban la vida del individuo, las pulsiones del yo, en realidad eran el camino a la muerte, eso sí, un camino elegido por el sujeto. "Bajo esta luz, la importancia teórica de las pulsiones de autoconservación, de poder y de ser reconocido, cae por tierra; son pulsiones parciales destinadas a asegu rar el camino hacia la muerte peculiar del organismo y a alejar otras posibilidades de regreso a lo inorgánico que no sean las inmanente" (39).

El capítulo VI está dedicado en su mayor parte en una especulación mediante la cual busca encontrar paralelismos entre la dicotomía pulsiones de vidapulsiones de muerte y la biología celular de la vida y la muerte. En medio de dicha especulación, Freud presenta ideas medulares acerca de la pulsión de muerte. En primer lugar, explica que esa separación previa, entre pulsiones sexuales y del yo o de autoconservación en realidad no se puede sostener en vista del narcisismo. Éste constituye un estado del yo en el que es depositario de la libido, tal como lo es un objeto externo.

El naricisismo, tal como Laplanche (7) ha señalado con toda claridad, es el estado inicial de la libido, y más adelante el yo podrá desprenderse se parte de esa libido para dirigirla a un objeto. Freud aplica el mismo razonamiento a una de las polaridades del amor y la pulsión sexual: la agresión, la destructividad, que es observable sólo cuando está dirigida al objeto. El origen de esa agresión no se puede explicar con su propia manifestación, es decir, debe preexistir aunque de un modo no observable. En un inicio esa carga pulsional está dirigida también al propio yo, pero debido a las pulsiones sexuales dirigidas al yo, las pulsiones de muerte son dirigidas al exterior.

El movimiento producido por la pulsión de muerte, paradójicamente, abre la vía para que le siga la pulsión sexual y, de hecho, facilita su acceso al objeto que la satisface. Es decir, Freud plantea como inevitable, al menos en las fases tempranas de la vida pulsional, la apropiación violenta del objeto de amor, planteamiento que tiene enormes implicaciones para, por ejemplo, la violencia de género.

Es importante el señalamiento que hace Laplanche (7) acerca de los usos de los términos agresión o destructividad, por un lado, y masoquismo y sadismo, por el otro. En la línea cronológica, la agresividad es la primera en aparecer, y está dirigida al exterior, pero, por un movimiento análogo al de la pulsión sexual, se repliegan en la naciente fantasía. En ese movimiento la agresividad se tiño de sexualidad, lo que da por resultado el masoquismo primario. Entonces, la diferencia entre agresividad y masoquismo es el carácter sexual que reviste a este último, es decir, una fusión del dolor con el placer, que más adelante será dirigido también al exterior en forma de sadismo.

El capítulo VII, Freud concluye planteándose preguntas sobre cómo entender la nueva polaridad pulsional en términos del principio de placer y los procesos primario y secundario. La tendencia de las pulsiones a reencontrar estados previos explicaría los casos en que el principio de placer no se cumple, como en la compulsión a la repetición.

\section{Comentarios finales}

Más allá del principio del placer planteó un cuestionamiento profundo acerca de la naturaleza de las pulsiones formulada en Pulsiones y destinos de pulsión. Hasta entonces, Freud había considerado principalmente la pulsión sexual como el factor que obliga a la acción del organismo y, por lo tanto, a la acción del yo. La búsqueda de satisfacción implica encontrar el objeto acorde con la pulsión, hacerlo accesible y ejecutar la acción específica. Lo que complica enormemente la comprensión de este circuito de descarga, es la diversidad de caras que adopta el placer: a nivel sensual o narcisista, y el que deriva de dominar al objeto, de dañarlo, de infligirle dolor físico o psíquico, o de destruirlo.

El recurso al nivel biológico para justificar y entender la dualidad pulsional frudiana, tiene notables limitaciones si aceptamos el planteamiento de Laplanche (7): la pulsión es la perversión del instinto. La dinámica del funcionamiento biológico del ser humano sufre una desnaturalización por efecto de la cultura $y$, particularmente, del lenguaje, que trae consigo una gama inagotable de posibilidades inéditas en el nivel biológico. Queda mucho por dilucidar acerca de este tema. Autores más recientes, como el propio Laplanche, han resaltado la idea freudiana -a veces contradicha por el propio Freudde que la pulsión tiene su génesis en la relación del bebé con sus cuidadores. En esos primeros contactos hay una seducción de la que no es consciente la madre, pero que es fundamental para la implantación de la sexualidad en el niño. El placer extra que experimenta el bebé se convierte en la fuente de la vida pulsional, tanto del Eros como del Tánatos, la cual converge en el mismo objeto. Inevitablemente, en sus primeros momentos de vida, el niño sólo puede fantasear con la destrucción del objeto que necesita y desea, el pecho materno, y esa fantasía 
deriva de la ausencia de dicho objeto. El amor y el odio están inextricablemente unidos desde sus orígenes; cuanto mayor es el amor, también lo es el potencial de odio (8). Y esta dinámica se observa no sólo en los niños pequeños, sino en adultos; es común encontrar casos en las noticias de, principalmente, hombres que asesinan a una mujer porque no quiso ser su pareja o porque ya no quiso seguir siendo su pareja. ¿Cuál es la dinámica pulsional de casos como esos? Otros casos de rupturas amorosas terminan con el suicidio de la persona abandonada. ¿Qué determina que en algunos casos el abandonado mate a su objeto de amor y en otros se mate a sí mismo? Es posible que no sean equivalentes las situaciones, es decir, que el suicidio no se perpetre como una venganza, sino como un intento desesperado por dejar de sufrir. Sin embargo, no se puede excluir el elemento de venganza sobre el objeto de amor, quien al menos en la fantasía del suicida sufrirá el remordimiento de haber provocado la muerte de aquel a quien rechazó. Freud (9) postuló que cada individuo dispone de una cantidad limitada de libido, la cual se distribuye entre el yo y sus objetos, por lo que investir con mayor cantidad a los objetos implica reducir la libido narcisista y viceversa. ¿Podría la pulsión de muerte entrar en esa misma lógica distributiva en que se incluyan ambos tipos de pulsiones? Es decir, que el aumento del amor implique una reducción del odio y viceversa. Hasta ahora, se ha asumido que son dos tipos de energía pulsional diferenciados e independientes, aun cuando coexistan e, incluso, se fundan en muchas ocasiones. Sin embargo, si se pudiera determinar que existe tal relación entre amor y odio, eso implicaría que existe una forma primitiva de energía psíquica indiferenciada que adquiere la forma del amor y odio dependiendo de circunstancias como, la disponibilidad del objeto, su disposición para dar la satisfacción requerida y, por supuesto, el tipo de estructuración del yo, que es la instancia que media entre las pulsiones y el mundo externo.

\section{Referencias}

1. Freud S. Formulaciones sobre los dos principios del acaecerpsíquico. En: Strachey J, editor. Obras completas. Buenos Aires, Argentina: Amorrortu; 1911.p. 217-32.

2. Freud S. Más allá del principio de placer. En: Strachey J, editor. Obra s completas. Buenos Aires, Argentina: Amorrortu; 1920.p. 1-62.

3. Freud S. Pulsiones y destinos de pulsión. En: Strachey J, editor. Obras completas. Buenos Aires, Argentina: Amorrortu; 1915.p. 105-34.

4. Freud S. La interpretación de los sueños. En: Obras completas. Buenos Aires, Argentina: Amorrortu; 1900.

5. Freud S. Recordar, repetir y reelaborar (Nuevos consejos sobre la técnica del psicoanálisis, II). En: Stra chey J, editor. Obra s completas. Buenos Aires, Argentina: Amorrortu; 1914.
6. Freud S. Proyecto de psicología. En: Strachey J, editor. Obras completas. Buenos Aires, Argentina: Amorrortu; 1895.

7. Laplanche J. Vida y muerte en psicoanálisis. Buenos Aires, Argentina: Amorrortu; 1970.

8. Klein M. Notes on Some Schizoid Mechanisms. En: Riviere J, editor. Developments in Psychoanalysis. London, UK: The Hofarth Press; 1952.p. 292-320.

9. Freud S. Introducción al narcisismo. En: Obras Completas. Buenos Aires, Argentina: Amorrortu; 1914.p. 65-98. 